\title{
Die Auswirkungen der Großen Rezession auf die europäischen Parteiensysteme
}

\author{
HANSPETER KRIESI
}

G emäß der Theorie des ökonomischen Wählens werden die Regierungsparteien von den Wählern belohnt, wenn es wirtschaftlich gut geht, und bestraft, wenn die Wirtschaft darnieder liegt. Diese Theorie wird durch die Wahlen weitgehend bestätigt, die seit dem Zusammenbruch der Investmentbank Lehman Brothers im Herbst 2008 und der damit einsetzenden Großen Rezession in den verschiedensten Ländern Europas stattgefunden haben. Praktisch überall in Europa hatte die Große Rezession sehr starke Auswirkungen auf die Wahlchancen der Regierungsparteien: je tiefer die Krise, desto stärker wurden sie von den Wählern bestraft. So erlebten etwa die griechischen Sozialisten (PASOK) einen Einbruch von mehr als 30 \% (2012), die irische Fianna Fáil von mehr als $20 \%$ (2011), oder der italienische Popolo della Libertà einen Verlust von immer noch mehr als $15 \%$ (2013). Auch wenn die Abstrafung der Regierungsparteien nicht überall diese extremen Größenordnungen erreicht hat, so wurden doch die meisten Parteien, die in den Krisenjahren regierten, für den wirtschaftlichen Einbruch zur Verantwortung gezogen. Deutschland ist in dieser Beziehung insofern eine Ausnahme, als die dominante Regierungspartei - die CDU/CSU und ihre Kanzlerin - praktisch ungeschoren durch die Krise kam, während ihre Koalitionspartner jeweils für die Regierungsbeteiligung in der Krise zu bezahlen hatten - zunächst die SPD (2009) und dann die FDP (2013).

Die Theorie ökonomischen Wählens hat allerdings nur eine kurzfristige Perspektive und geht davon aus, dass die Wahlerfolge der etablierten Parteien ein Nullsummenspiel mit wechselnden Vorzeichen darstellen: Wenn die Regierungsparteien abgestraft werden, dann gewinnt die etablierte Opposition und umgekehrt. In den genannten Fällen hat die Bestrafung der Regierungsparteien in der jüngsten Krise aber Proportionen erreicht, die weit über konjunkturelle Schwankungen hinausgehen und geradezu das Überleben der betroffenen Parteien infrage stellen. Bemerkenswert an der jüngsten Krise ist zudem, dass die etablierten Oppositionsparteien, die üblicherweise vom Einbruch der Regierungsparteien am meisten profitieren, in vielen Ländern ebenfalls nicht ungeschoren davongekommen sind. So haben etwa die etablierten griechischen und italienischen Oppositionsparteien (Nea Demokratia bzw. Partito Democratico) in den Wahlen 2012/13 ebenfalls deutliche Einbußen erlitten.

Tatsächlich bietet die Krise eine einmalige Chance für den Aufstieg von neuen Parteien oder von bereits mehr oder weniger etablierten populistischen Herausforderern. Dabei ist zu unterscheiden zwischen den Ländern Süd- und Osteuropas einerseits und Nordwesteuropas andererseits. In den Ländern Süd-und Osteuropas waren aufgrund der geringen Institutionalisierung der Parteiensysteme und der weit verbreiteten Korruption unter den Regierungsparteien kurzlebige neue Parteien von mehr oder weniger populistischen Herausforderern schon vor der Krise punktuell sehr erfolgreich. In den von der Krise besonders stark betroffenen Ländern dieser Regionen erhielten neue Populisten vor allem von links (in Südeuropa) und von links bis rechts (in Osteuropa) in der Krise zum Teil starken Auftrieb. Das Resultat ist eine anhaltend hohe Volatilität der
Parteiensysteme, die vor allem auf den Erfolg immer wieder neuer Herausforderer zurückzuführen ist.

In Nordwesteuropa, das von der Krise (mit Ausnahme von Irland und Island) weniger bzw. indirekter betroffen war als Süd-und Osteuropa, hat ein längerfristiger struktureller Wandel der Parteiensysteme schon einige Zeit vor der Krise eingesetzt: So haben sich in vielen Ländern dieser Region rechtspopulistische Herausforderer, welche in erster Linie die Anliegen der sogenannten „Globalisierungsverlierer" mobilisieren, dauerhaft etabliert und zur längerfristigen Erosion der etablierten Parteien beigetragen. Zu denken ist dabei etwa an den Front National in Frankreich, die schweizerische SVP, die österreichische ÖVP, die holländische PVV, den Flämischen Block in Belgien, die Dänische Volkspartei oder die norwegische Fortschrittspartei. Die Krise bietet auch für diese Rechtspopulisten in Nordwesteuropa eine einzigartige Chance, sich von früheren Misserfolgen zu erholen oder sich weiter zu verstärken. So kam es in den jüngsten Europawahlen zu einem spektakulären Comeback des Front National in Frankreich, der mit 24,9\% zur stärksten Partei wurde. Zudem erhielten die Rechtspopulisten in denjenigen Ländern Nordwesteuropas, in denen sie sich in der Vergangenheit noch nicht so stark entwickeln konnten, die Chance, ihren Entwicklungsrückstand wettzumachen. So erlebten die „Wahren Finnen“ 2011 vor dem Hintergrund der Eurokrise einen spektakulären Aufstieg (2007: 19,1\%) ebenso wie die Schwedendemokraten in den schwedischen Wahlen in diesem Herbst (12,9\%). Zum wenn möglich spektakulärsten Erfolg kam aber die britische UKIP, die mit 26,8\% in den letzten Europawahlen zur stärksten Partei Großbritanniens wurde. Auch der Erfolg der Alternative für Deutschland ist schließlich vor diesem Hintergrund zu sehen. Sie bildet das funktionale Äquivalent der Rechtspopulisten in den benachbarten Ländern. Zwar hatte sie bei den Bundestagswahlen 2013 die 5\%-Hürde noch nicht genommen, aber bereits in den Europawahlen im Frühling 2014 erzielte sie bundesweit 7,1\%, und in den kürzlichen Landtagswahlen in Sachsen, Brandenburg und Thüringen kam sie auf 9,7 bis 12,2\%. Damit hat der allgemeine Trend einer Restrukturierung der europäischen Parteilandschaften im Zeichen der Globalisierung (in Europa in erster Linie im Zeichen der Europäisierung) auch das bislang extrem stabile deutsche Parteiensystem erreicht. Aus meiner Sicht dient die Krise in Nordwesteuropa mit anderen Worten als Katalysator für die grundlegende Restrukturierung der Parteiensysteme durch den Konflikt zwischen defensiven national-konservativen Strömungen einerseits und offensiven kosmopolitisch-multikulturellen Positionen andererseits.

HANSPETER KRIESI ist Professor für vergleichende Politikwissenschaft am Europäischen Hochschulinstitut in Florenz und forscht für den Europäischen Forschungsrat (ERC) zu den politischen Folgen der Großen Rezession in Europa.

hanspeter.kriesi@eui.eu 